\title{
The Role of the Male Partner in the Prevention of Mother to Child Transmission of HIV in Cameroon
}

\author{
Dickson Shey Nsagha ${ }^{1, *}$, Gregory Edie Halle-Ekane ${ }^{2}$, Claude Shei Nfor ${ }^{2}$, Marcelin Ngowe Ngowe², Boniface \\ Tatchwanglie Nasah ${ }^{2}$ \\ ${ }^{1}$ Department of Public Health and Hygiene, Faculty of Health Sciences, University of Buea, Buea, Cameroon \\ ${ }^{2}$ Department of Surgery, Obstetrics and Gynaecology, Faculty of Health Sciences, University of Buea, Buea, Cameroon \\ *Corresponding author: nsaghads@hotmail.com; dsnsagha@gmail.com
}

Received October 10, 2013; Revised March 13, 2014; Accepted March 14, 2014

\begin{abstract}
Background: Mother to child transmission of HIV remains a major public health problem. To solve this problem WHO developed the PMTCT program. Involving male partners in the program is associated with improved outcome. However, in Cameroon, only 1.6\% of men participated in the program in 2010 and the program's target of $80 \%$ was not reached. Hence, this study sought to assess the knowledge, attitudes and practices of men with regards to PMTCT in the Buea Health District of Cameroon. Methods: It was a cross sectional survey of 384 community men and 384 women attending ANC/PMTCT and IWF clinics in the Buea Health District using a structured questionnaire. Ethical clearance was obtained from the FHSIRB. Each health area in the district represented a stratum. In each stratum, there was sampling of women at the clinics and men in the community. Written consent was obtained from all participants. Data was analysed on EPI INFO version 3.5.1. Results: More than $81 \%$ of respondents had heard of the PMTCT program (95\%CI: 93.5-97.9\%). However, the proportion of men and women with correct knowledge of PMTCT was less than the $80 \%$ target (95\%CI: $72.5 \%-81.2 \%$ for men and $68.2-77.4 \%$ for women). The health services $(\mathrm{p}=0.0001)$, radio and television $(\mathrm{p}=0.0001)$ were the main sources of information on PMTCT. Attitudes towards PMTCT program activities and male involvement was largely positive. Male participation at ANC/PMTCT clinic was low (41.3\%). Non-invitation to clinic and lack of time were the main reasons for low male participation. Use of condom during pregnancy and breastfeeding was low (74.5\%) and practice of multiple sexual partners was common in the district. Community sensitisation, creation of clinic days for men and participation of couples at ANC clinics were proposed methods for improving male participation. Conclusion: Men have a role to play in PMTCT and should be given adequate knowledge of PMTCT for improved outcome.
\end{abstract}

\section{Keywords: HIV, AIDS, PMTCT, men, women, Cameroon}

Cite This Article: Dickson Shey Nsagha, Gregory Edie Halle-Ekane, Claude Shei Nfor, Marcelin Ngowe Ngowe, and Boniface Tatchwanglie Nasah, "The Role of the Male Partner in the Prevention of Mother to Child Transmission of HIV in Cameroon." American Journal of Epidemiology and Infectious Disease, vol. 2, no. 2 (2014): 52-59. doi: 10.12691/ajeid-2-2-1.

\section{Introduction}

Since the beginning of the HIV pandemic, nearly 2.7 million children are currently living with HIV/AIDS; most of them had acquired the virus before birth, during labour and delivery or through breast feeding [1]. In 2008 alone, 430,000 children became infected with HIV, mainly through mother-to-child transmission (MTCT) [2]. About $90 \%$ of MTCT of HIV occurs in Africa where AIDS is beginning to reverse decades of steady progress in child survival [2].

In Cameroon the prevalence of HIV is 5.3\% [3]. The prevalence among pregnant women is $4.4 \%$ [3]. There were 54,000 children age $0-14$ years living with HIV by 2009 and 10,900 new paediatric infections in 2009 [3]. Modelled UNAIDS data indicates that if interventions are scaled up to global plan targets between 2010 and 2015, there would be $83 \%$ decline in new paediatric infections in 2015 [3]. Five years after introduction of PMTCT program in 2000, progress has been timid and non involvement of the male partner was identified as one of the retarding factors. The Cameroonian Ministry of Public Health therefore called for increased involvement of the male partner in PMTCT program to improve uptake [4]. Five years after the call, in 2010, only $1.6 \%$ of partners of pregnant women had VCT for PMTCT in Cameroon and only one or two couples were seen at ANC every month [5]. Uptake of PMTCT services amongst pregnant women remained low. In 2009, only $41 \%$ of pregnant women were tested for HIV at ANC [6]. In 2011, only 54\% of HIV positive pregnant women and $27 \%$ of their babies received ARV coverage for PMTCT [7].

In the South West Region of Cameroon, the HIV prevalence in the general population is $8 \%$ [8], 7.9\% amongst pregnant women at first ANC visit and $16.6 \%$ at labour [9]. There were 1,145 babies born to HIV positive 
mothers in 2010 [9]. The high prevalence of HIV in pregnancy and high fertility rate amongst HIV positive women makes the region a high risk zone for vertical transmission of HIV.

In the Buea Health District, there were 165 positive pregnant women and 162 babies born to positive mothers [9]. At 6weeks, 37 exposed infants were tested for HIV with PCR and 13 were reported positive. At 12 months, 40 exposed babies were tested with PCR and 18 were reported positive [9]. This gives a transmission rate of $31.5 \%$ at 6 weeks and $45 \%$ at 12 months after birth in 2010 . These rates were similar to the $45 \%$ rate reported for Cameroon in 2002 [10]. Therefore, the Buea Health District at the end of 2010 was far from attaining the 50\% target for reducing the rate of mother- to- child transmission of HIV.

In Botswana, following integration of male partners in PMTCT education programs, uptake of HIV testing within PMTCT has increased from 49\% in 2002 to $83 \%$ in 2008. Even more notably, mother- to- child transmission has reduced from an estimated $30-40 \%$ before the interventions to 4\% in 2008 [11]. Men are often presented as an obstacle in PMTCT programs [12]. Focus of health services has been on women and children hence failure to target men. This creates a gap in interventions since men can significantly influence their partner's reproductive health decisions and use of health resources. Overlooked is the potential of men to provide valuable support to HIV infected women as they attempt to prevent HIV transmission to their children. Participation of HIV infected women in PMTCT is simplified when male partners know their role in prevention and are unwilling to commit the necessary resources [12]. There is paucity of data on the appropriate knowledge of PMTCT by men, their participation and that of their spouses on PMTCT in Buea. The level of awareness of PMTCT issues amongst men in the Buea Health District is not known. This study was conducted to assess the knowledge, attitudes and practices of male partners with regards to the prevention of mother- to- child - transmission of HIV.

\section{Methods}

\subsection{Study Area}

We conducted a cross sectional survey in the South West Region which is one of the ten regions of the Republic of Cameroon. Buea is the political capital of the South West Region. Buea is bounded to the North by tropical rain forest on the slopes of Mt. Cameroon. The town also shares boundaries with other major towns like Limbe to the Southwest, Tiko to the Southeast, Muyuka to the East and Idenau to the West. The Buea Health District (BHD) is situated in Fako Division and covers Buea SubDivision except Idenau and Bojongo Health Areas, which are under the Limbe Health District. BHD is made up of seven Health Areas namely: Bokwaongo, Bova, Buea Road, Buea Town, Molyko, Bokova and Muea. The population is heterogeneous. The study was conducted over a period of 3 months: July, August and September 2012. This study involved women with babies at risk of mother-to-child transmission of HIV who were either pregnant or breast feeding. They were selected from the
Muea Health Centre, the Buea Town Health Centre, the Buea Road Health Centre, the Bokwango Health Centre, the Bonakanda Health Centre, the Molyko Health Centre and the Buea Regional Hospital.

\subsection{Criteria for Inclusion and Exclusion of Participants}

The inclusion criteria were women who were registered for ANC or IWF attendants at the selected health facilities. Women who gave a written consent were recruited for the study. The male population included Men in Buea Health District community.

The inclusion criteria for men were those with at least a child or pregnant partner after the introduction of PMTCT program in 2000. This group of men was selected because they were expected to have had an experience with the PMTCT program.

\subsubsection{Sampling of Participants}

\subsubsection{Sampling of Women}

The Buea Health District comprises of seven health areas with several ANC and IWF centers. The Health District was divided into seven strata. Each health area represented a stratum. At least one ANC and IWF centre which offer PMTCT services was purposively selected in each health area and ANC and IWF attendees at selected health centres were interviewed.

\subsubsection{Sampling of Men}

The population of the Buea Health District is divided into several quarters. The health district was divided into strata as described above. From each health area three quarters were randomly selected using the lottery method as follows: The name of each quarter in every health area was written on a piece of identical paper. One blinded person then picked any three pieces of paper. The three quarters whose names appeared on the pieces of paper picked were included in the study. The process was then repeated in each health area until all the quarters involved in the study were selected. Men were selected from 27 quarters.

\subsubsection{Calculation of the Sample Size}

The proportion of men and women with appropriate knowledge of PMTCT in the district is not known; by default a $50 \%$ proportion was considered.

$$
S=\frac{z^{2} p(1-p)}{d^{2}}
$$

Where $\mathrm{S}$ = sample size

$\mathrm{Z}=$ standard normal variate (1.96) at 95\% confidence interval.

$\mathrm{P}=$ a rough approximation to the proportion (50\%)

$\mathrm{d}=$ sampling error that can be tolerated (5\%)

$\mathrm{S}=(1.96)^{2}(0.5)(1-0.5) /(0.05)^{2}$ hence $\mathrm{S}=384$ men and 384 women

\subsubsection{Sample size for Each Health Area}

The proportion of the sample size represented by each health area corresponded to the proportion of the total population of the district $(\mathrm{N}=76950)$ represented by the health area is shown in Table 1. 
Table 1. Corresponding sample size for each health area

\begin{tabular}{|c|c|c|c|c|c|c|c|}
\hline Health area & Bokwango & Bova & Buea road & Buea town & Bokova & Molyko & Muea \\
\hline Population & 11007 & 1901 & 17058 & 15440 & 3909 & 8077 & 19558 \\
\hline Minimum Sample size & 55 & 9 & 85 & 77 & 19 & 40 & 97 \\
\hline
\end{tabular}

\subsubsection{Data Collection Tools}

The study questionnaire was adapted from that used for a similar study at the University of Witwatersrand, Faculty of Health Sciences, and School of Public Health, Johannesburg in South Africa [13]. The questionnaire had in-depth questions to assess knowledge, attitude and practices of respondents and their opinion of male participation in the PMTCT program. All field staff were adequately trained on the research topic using the adult learning methods such as presentations, role plays and question and answer sessions.

\subsubsection{Research Procedures at the Community Level}

The team of researchers visited the quarters using the quarter heads as the entry points into the community. Designated representatives informed the community members of their presence and called for their cooperation. The study being cross sectional, offered the advantage that we could draw a large sample size. Besides, the respondents felt more secured giving information as their identities were not given in the questionnaire. A pilot study was carried out on 25 women and 50 men in one quarter in the Muea Health Area to validate the questionnaire (this quarter was left out of the study to avoid bias).

\subsubsection{Participant Selection Procedures}

The research team visited the health centres on ANC and IWF clinic days to meet the women. At the health centre the selection of women was randomized by counting the women according to their sitting position. The women with even number counts were included in the study. This was repeated on each visit until the sample size for the health area was attained.

The research team visited the communities early in the morning and in the evenings to meet the men at home. The pilot study revealed that most men in the community would leave their homes for work after 10.00 a.m and would be back by 4.00 p.m. In each quarter included in the study, selection of the men was randomized by starting from a randomly selected household along the road. Every even number house count on the both sides was selected. One man from each household who met the criteria of inclusion was selected. This was done until the sample size for the health area was met.

\subsubsection{Procedures for Administration of the Questionnaire}

Participants were presented with the informed consent/assent document after introduction of the study. Verbal clarification was provided in case of doubts. The participants then signed the consent form to participate in the study. Where an assent form was used, the legal guardian was asked to sign. The interview technique was used for data collection. For those who knew not how to read or write, their literate relations or research field workers assisted them to complete the questionnaire.

\subsubsection{Ethical Considerations}

Ethical Clearance was sought from the Institutional Review Board of the Faculty of Health Sciences of the University of Buea. Administrative authorization was sought from the Regional Delegation of the Ministry of Public Health and the District Health Service.

The purpose of the study alongside the role of the participants were well explained in the consent/assent form to the participants and participation could only take place after the participant had read and signed the informed consent/assent form voluntarily. The questionnaire was strictly anonymous

\subsubsection{Data Management and Analysis}

Each member of the data collection team was obliged to check each questionnaire for filling errors, correct coding and completeness in the presence of the respondents so that all inconsistencies were verified with the respondent before leaving. At the end of each working day, each member of the data collection team submitted the filled questionnaires to one of the investigators. After the submissions, the questionnaires were further checked for filling errors, correct coding, completeness and inconsistencies. Any errors identified were identified by sending field staff back to the community or ANC clinic for correction of the filled questionnaire. A data entry sheet was created in EPI INFO version 3.5.1. Each day, data collected was entered into the data entry sheet to create a data base. Access to the data base was limited to researchers by a code for security reasons. The analysis of the data was done using EPI-INFO version 3.5.1. Descriptive statistics were depicted using absolute numbers, simple percentages, range and measures of central tendency (mean, median) as appropriate. Chisquare test and Fisher exact test were used when necessary to examine the relationship between variables. Statistical significance was achieved with $\mathrm{P}<0.05$.

\section{Results}

\subsection{Socio Demographic Characteristic}

During the study, 384 women and 384 men were interviewed. The age range of the women was 15 to 40 years with mean of $25.4(\mathrm{SD}=4.6)$. The mean age of men was 35.9(SD=7.8) years with range 16 to 60years (Table 2).

Table 2. Distribution of educational and marital status by sex of study participants

\begin{tabular}{lll}
\hline Parameter & Men N (\%) & \multicolumn{1}{c}{ Women N (\%) } \\
\hline Educational level & & \\
Above secondary school & $108(28.1)$ & $78(20.3)$ \\
Completed secondary school & $100(26.0)$ & $149(38.9)$ \\
Completed primary school & $161(42.0)$ & $146(37.9)$ \\
No formal education & $15(3.9)$ & $11(2.9)$ \\
Total & $\mathbf{3 8 4 ( 1 0 0 )}$ & $\mathbf{3 8 4 ( 1 0 0 )}$ \\
Marital status & & \\
Married & $\mathbf{2 8 8 ( 7 4 . 9 )}$ & $274(71.3)$ \\
Single /divorced & $96(25.1)$ & $110(28.7)$ \\
Total & $\mathbf{3 8 4 ( 1 0 0 )}$ & $\mathbf{3 8 4 ( 1 0 0 )}$ \\
\hline
\end{tabular}




\subsection{Respondents Who Had Heard of the PMTCT Program}

There were 313(81.5\%) men and 309(80.4\%) women who had heard about the PMTCT program. Married men were more likely to know of the PMTCT program than single men $\left(\chi^{2}=9.0 ; \mathrm{P}=0.002\right)$ as $84.8 \%$ of married men were aware of the program compared to $70.7 \%$ of single men Table 3 shows that the media and health services were the leading sources of information on PMTCT.

Table 3. Distribution of sources of information on PMTCT by sex of respondents

\begin{tabular}{|c|c|c|c|c|c|}
\hline \multicolumn{6}{|c|}{ WOMEN } \\
\hline Coumer of DMTCT informotion & Peers & Health services & Partners & Media & Others \\
\hline Source of PMTCT information & N (\%) & N (\%) & N (\%) & N (\%) & N (\%) \\
\hline Used & $35(9.1)$ & 211(54.9) & $2(0.5)$ & $123(32.0)$ & $13(3.4)$ \\
\hline TOTAL & 384(100) & $384(100)$ & $384(100)$ & 384(100) & 384(100) \\
\hline \multicolumn{6}{|c|}{ MEN } \\
\hline Used & 41(10.7) & $109(28.4)$ & $11(2.9)$ & 207(53.9) & $2(0.5)$ \\
\hline TOTAL & $384(100)$ & $384(100)$ & $384(100)$ & $384(100)$ & $384(100)$ \\
\hline$\chi^{2}$ & 0.5 & 55 & 6.3 & 37.5 & 8.2 \\
\hline$P$ value & 0.5 & 0.0001 & 0.01 & 0.0001 & 0.004 \\
\hline
\end{tabular}

\subsection{Assement of Knowledge of PMTCT of} Study Participants

In this study, 369(96.1\%) men had correct knowledge of HIV transmission during unprotected sex, giving a 95\% CI of $93.5 \%$ - 97.7\% compared to 370 (96.3\%) women with a 95\% CI of 93.8\% - 97.9\%. There were 296(77.1\%) men with correct knowledge on prenatal transmission of $\mathrm{HIV}$ to babies, giving a $95 \%$ CI of $72.5 \%-81.2 \%$ compared to $280(73.0 \%)$ women with a $95 \%$ CI of $68.2 \%$ 77.4\%. We had 285(74.2\%) men with correct knowledge on HIV transmission during breastfeeding, giving a 95\% CI of $69.5 \%-78.5 \%$ compared to $280(73.1 \%$ ) women with a $95 \%$ CI of $68.3 \%-77.4 \%$. It was also found that $164(42.8 \%)$ men had correct knowledge of increase risk of HIV transmission with mixed feeding giving a 95\% CI of $37.8 \%-48.0 \%$ contrary to $204(53.1 \%$ ) women with a $95 \%$ CI of $48.0 \%-58.2 \%$. Also, there were $121(31.5 \%)$ men who had correct knowledge on the use of caesarean section for PMTCT giving a 95\% CI of 26.9\% $-36.5 \%$ contrary to $207(53.9 \%)$ women with a $95 \%$ CI of $48.8 \%$ $59 \%$. It was also documented that 303(78.8\%) men had correct knowledge of the use of ARV for PMTCT giving a 95\% CI of $74.4 \%$ - $82.8 \%$ compared to $330(85.9 \%)$ women with a $95 \%$ CI of $82 \%-89.2 \%$. In addition, there were $199(51.8 \%)$ men with correct knowledge of whether an HIV infected couple could have a child without HIV giving a $95 \%$ CI of $46.7 \%$ - 56.9\% compared to $247(64.3 \%)$ women with a $95 \%$ CI of $59.2 \%-69.1 \%$ (Table 4). It was statistically significant to conclude that women had more correct knowledge of PMTCT compared to the men. There were 246 (60\% - 68.9\% at 95\% CI) men who had correct knowledge of PMTCT compared to $274(66.9 \%-75.5 \%$ at $95 \% \mathrm{CI})$ women $\left(\chi^{2}=4.7 ; \mathrm{P}=0.03\right)$. However, the proportion of both men and women who had correct knowledge of PMTCT was less than the $80 \%$ target for 2010.

Table 4. Variation of some determinants of knowledge of PMTCT by sex of respondents

\begin{tabular}{|c|c|c|c|c|c|}
\hline \multirow[b]{3}{*}{ DETERMINANTS } & \multicolumn{4}{|c|}{ RESPONSE } & \multirow[b]{3}{*}{$\chi^{2}(\mathrm{P})$} \\
\hline & \multicolumn{2}{|c|}{$\begin{array}{c}\text { Correct } \\
\text { N (\%) }\end{array}$} & \multicolumn{2}{|c|}{$\begin{array}{c}\text { Incorrect } \\
\mathrm{N}(\%)\end{array}$} & \\
\hline & Men & Women & Men & Women & \\
\hline HIV is transmitted during unprotected sex & $369(96.1)$ & $370(96.3)$ & 15(3.9) & $14(3.7)$ & $0.04(0.8)$ \\
\hline HIV is transmitted at pregnancy to unborn baby & $296(77.1)$ & $280(73.0)$ & $88(22.9)$ & 104(27) & $1.8(0.1)$ \\
\hline HIV is transmitted at lactation & 285(74.2) & 280(73.1) & $99(25.8)$ & 104(26.9) & $0.2(0.7)$ \\
\hline Mixed feeding increases transmission rates & $164(42.8)$ & 204(53.1) & $220(57.2)$ & 180(46.9) & $8.4(0.004)$ \\
\hline Caesarean section reduces transmission at delivery & 121(31.5) & 207(53.9) & 263(68.5) & 177(46.1) & $39(0.001)$ \\
\hline ARV prophylaxis prevent transmission to the child & 303(78.8) & $330(85.9)$ & $81(21.2)$ & $54(14.1)$ & $6.6(0.01)$ \\
\hline HIV infected couple can have a baby who is not infected & 199 (51.8) & $247(64.3)$ & $185(48.2)$ & $137(35.7)$ & $12(0.001)$ \\
\hline
\end{tabular}

\subsection{Experiences with the Practice of PMTCT in the Buea Health District}

In this study, 267(69.9\%) women had their partners invited to the ANC clinic and 114(42.8\%) participated giving a $95 \%$ CI of $36.7 \%-49.1 \%$. Amongst the 384 community men, 153(39.8\%) had also participated at ANC/PMTCT clinic giving a 95\% CI of 34.8\%-45.0\% (Table 5).

Generally male partner participation at ANC/PMTCT clinics in the Buea Health District is low. According to the women, $42.8 \%$ had their partners come along with them for PMTCT during pregnancy. For the men, 39.8\% had accompanied partner for PMTCT. Averagely male participation in PMTCT stands at $41.3 \%$ in Buea Health District.

Table 5. Variation of women's experiences with PMTCT and some determinants

\section{DETERMINANTS}

Counselled on PMTCT

Partner invited

Educate partner at home

Difficulties with partner education

Perceive partner as a barrier to PMTCT

Male partner participation

Women whose partners came for VCT

Men who came for VCT/PMTCT

\begin{tabular}{cc}
\multicolumn{2}{c}{ EXPERIENCES } \\
\hline Involved & Not involved \\
$\mathrm{N}(\%)$ & $\mathrm{N}(\%)$ \\
$247(64.3)$ & $137(35.7)$ \\
$267(69.6)$ & $117(30.4)$ \\
$321(83.5)$ & $63(16.5)$ \\
$74(23)$ & $247(77)$ \\
$96(25.1)$ & $288(74.9)$ \\
& \\
$114(42.8)$ & $153(57.2)$ \\
$153(39.8)$ & $231(60.2)$ \\
\hline
\end{tabular}




\subsection{Improving Male Participation in the PMTCT Program}

In seeking opinion on improving male involvement at PMTCT, three main propositions were made: community sensitization of men, the necessity for men to accompany their partners for PMTCT at the ANC clinic and the creation of special clinic days for men. The popularity of each method differed amongst the male and female respondents (Table 12).

Table 12. Distribution of methods for improving male participation in PMTCT by sex of respondents

\begin{tabular}{lcccc}
\hline \multirow{2}{*}{ METHOD } & \multicolumn{2}{c}{ MEN } & \multicolumn{2}{c}{ WOMEN } \\
\cline { 2 - 5 } & YES & NO & YES & NO \\
Community sensitization & $43.5 \%$ & $56.5 \%$ & $24.2 \%$ & $75.8 \%$ \\
Compulsory for men to come & $37.8 \%$ & $62.2 \%$ & $34.9 \%$ & $65.1 \%$ \\
with partners & $20.1 \%$ & $79.9 \%$ & $41.9 \%$ & $58.1 \%$ \\
Create clinic days for men & & & & \\
\hline
\end{tabular}

\section{Discussion}

In this study, the marital status, age group and educational level of respondents were independent sociodemographic variables that were found to affect different aspects of respondent's knowledge, attitudes and practices of PMTCT. There were $81 \%$ respondents who had already heard of the PMTCT program. This popularity was not reflected in the $41.3 \%$ male participation at ANC/PMTCT clinics. This disparity was consistent with other findings in Cameroon where most men considered accompanying their wife to ANC a good practice yet fewer men actually did so [14]. In another study in Botswana, $82.1 \%$ of men had already heard of the program but participation was low [13]. Similar findings were reported in Dar es salaam and Mbeya in Tanzania $[15,16]$. Therefore, the general trend indicates that low male participation could not have been because they have not heard of the PMTCT program but for other reasons.

The health service was the main source of knowledge on PMTCT for women in the Buea Health District. This finding was consistent with reports from Mwizi subcounty in Uganda [17] and Botswana [13]. For the men, the media was the main source of information on PMTCT. This finding is consistent with those from Botswana [13]. This reveals that the direct contact between men and health workers is limited in the BHD and focus is on women. The fact that the Health Service is the main source of information on PMTCT for the women exposes them to first hand information while the men get incomplete information from the media. This could explain why more women had appropriate knowledge of PMTCT than men. Interestingly, we noted that only $2.9 \%$ men cited the female partner as source of information on PMTCT. Therefore, couple communication on PMTCT was low. The health personnel should focus on the men not depending on the women as intermediary as there is no guarantee that information given to women will reach their partners. Peer education on PMTCT was low as 9.1\% women and $10.7 \%$ men had PMTCT information from peers. This was consistent with findings from Mwizi sub county Uganda where 6.7\% respondents had information from their friends, relatives and social gatherings [17] and from Botswana [13]. This trend indicates that PMTCT is not a common topic of discussion amongst peers in the community.

The UNGASS for HIV/AIDS declared that in order to achieve a $50 \%$ reduction in the proportion of children living with HIV/AIDS by 2010, 80\% ANC/PMTCT attendee should have correct knowledge of PMTCT [18]. In BHD, the proportion of men and women with correct knowledge of PMTCT was less than the $80 \%$ target for 2010. The proportion of men and women with correct knowledge of PMTCT in BHD (95\%CI of 60\%-68.9\% and $66.9 \%-75.5 \%$ respectively) was lower than the $88 \%$ and $90.3 \%$ adequate knowledge of PMTCT reported in Mwizi sub-county in Uganda [17], and the 80\% report from Jawneng in Botswana [13]. This low level in BHD is probably because intervention programs to improve male participation has not been established unlike in Kenya, Tanzania, and Botswana where program targeting male participation has been established. This could also be because PMTCT nurses do not have correct knowledge of PMTCT as reports from Cameroon show that less than $70 \%$ of PMTCT nurses had correct knowledge of PMTCT [19].

We also found that $69.9 \%$ of women were asked to bring their partner for PMTCT/ VCT and only 42.8\% of the partners came. Similar findings were seen in Tanzania where $95.5 \%$ of women were asked to bring their partners to the ANC clinic but only 3\% of partners showed up [20]. Hence, it takes more than just invitation to have the men come to clinic. Health intervention strategies have to explore other options to have the men participate in PMTCT.

Men were involved in making decisions on issues affecting MTCT of HIV like permitting their partners to take HIV test, deciding on breastfeeding and delivery methods. This was consistent with findings in Tanzania where $78.6 \%$ of all women who accepted an HIV test at ANC asked permission from their partners [20]. It is therefore important to equip the men with correct knowledge of PMTCT for informed decision making. Equipping the men with correct knowledge means PMTCT nurses should themselves have correct knowledge of PMTCT as report from 70 rural health centres in Cameroon revealed that amongst 137 nurses, only $19 \%$ chose the right recommendation on infantfeeding for HIV-positive mothers. Lack of time and non invitation to clinics were the major reasons for low male participation in PMTCT. This finding was similar to reports from Dodoma in Tanzania [21] and Eastern and Northern Uganda where lack of time and non- invitation to clinics were reported as reasons for low male participation [22]. This reveals that there is a problem of timing because men do not have a time table for participation at ANC/PMTCT when the partner is pregnant; hence, they get involved in other activities and invitation to clinic always conflicts with these activities.

In the $\mathrm{BHD}$, the practice of multiple sexual partners was common amongst men and women especially amongst single men and women. Condom use amongst couples during breastfeeding and pregnancy was low (55.9\% and 23.2\% respectively). There were two reasons documented for lower condom use at pregnancy: the belief that the husband needs to continue to fertilise the baby for proper development and the belief that continuous 
unprotected sexual intercourse facilitates delivery. It was also established that the two reasons promoting condom use during breastfeeding were: the belief that semen spoils breast milk and that condoms are used to prevent maternal contact with semen. The use of condom during breastfeeding was also for contraceptive purposes. The high risk sexual behaviour amongst couples in BHD, may explain the high prevalence of HIV amongst pregnant women tested at labour in the region.

In seeking solution to improving male involvement at PMTCT, three main propositions were made: community sensitization of the men, the necessity for men to accompany their partners for PMTCT and the creation of special clinic days for men. These findings were important because where these intervention strategies have been used, PMTCT outcome was improved [21,22]. ANC providers, community leaders and community volunteers conducted a sensitization campaign on the importance of male partner support in Nzega District Tanzania [23]. Following this intervention uptake of HIV test amongst pregnant women increased from $22 \%$ before the intervention to $57 \%$ after the campaign. The proportion of HIV exposed infants on ARV prophylaxis increased from $35 \%$ to $41 \%$ and the proportion of children tested for HIV increased from $28 \%$ to $38 \%$ [23]. Similar findings were also reported in Northern Nigeria where following community sensitization to improve male partner support for PMTCT, HIV testing amongst pregnant women increased from $40 \%$ to $96 \%$ [24]. Also, intervention strategies targeted towards male partner participation at ANC/PMTCT clinic in Tanzania also had positive outcome as male participation increased from $7 \%$ before the intervention to $50 \%$ after the intervention [25]. The trends indicate that the proposed methods have been shown to improve male involvement and PMTCT program outcome. Therefore a multifaceted program integrating all these methods may help improve male involvement in PMTCT and the PMTCT program outcome in the Buea Health District.

\section{Conclusion}

Men have a role to play in PMTCT and as such, they should be given adequate knowledge of PMTCT for improved outcome

\section{Recommendations}

There should be routine HIV counselling and testing of couples during pregnancy and breastfeeding. The routine use of condom during pregnancy and breastfeeding for primary prevention of maternal HIV infection for couples with risky sexual behaviour is encouraged.

Community sensitization should be intensified with the creation of men's PMTCT clubs where men come together and discuss issues concerning PMTCT with PMTCT nurses. Women on the other hand need to be educated on their rights to take decision on matters concerning their health so that they do not need to take permission from male partners before taking HIV test.

The government and health development partners should identify the necessity of male participation at ANC clinics when the female partner is pregnant by developing policies that permit men to attend clinics even during working hours for counselling and testing for HIV. A national programme for integration of men should be designed where male partners are routinely expected at some stage of pregnancy and breastfeeding for counselling and VCT. Upgrading training and communication skills to both health care providers and media experts on PMTCT programme would be good.

A case control study needs to be done to compare PMTCT outcome at clinics where only couple oriented counselling is done and clinics where couple oriented counselling is not emphasized.

\section{Competing Interest}

The authors declare that they have no competing interests.

\section{Authors' Contribution}

NDS participated in the conception, design, implementation of the study, data analysis/interpretation and drafting the manuscript; GEHE participated in the conception, design, supervision of the study, interpretation of the data and drafting the manuscript. CSN participated in the conception, design, implementation of the study, data analysis, data interpretation and drafting the manuscript. NNM and BTN participated in the conception, design and data interpretation. All authors read and approved the final manuscript.

\section{Acknowledgements}

We would like to thank the men, women and research assistants who participated in the study. We acknowledge the advice and assistance of Dr Julius Atashili in the study design and data analysis. We appreciate the contribution of all Clinic Heads and community leaders of the Buea Health District in data collection.

\section{List of Abbreviations}

$\begin{array}{ll}\text { AIDS } & \text { Acquired Immune Deficiency Syndrome } \\ \text { ANC } & \text { Antenatal Care } \\ \text { ART } & \text { Antiretroviral Therapy } \\ \text { ARV } & \text { Anti-retrovirals } \\ \text { BHD } & \text { Buea Health District } \\ \text { HIV } & \text { Human Immunodeficiency Virus } \\ \text { IWF } & \text { Infant Welfare } \\ \text { KAP } & \text { Knowledge, Attitudes and Practices } \\ \text { MCH } & \text { Maternal and Child Health } \\ \text { MDG } & \text { Millennium Development Goal } \\ \text { MTCT } & \text { Mother- to- Child Transmission } \\ \text { PCR } & \text { Polymerase Chain Reaction } \\ \text { PMTCT } & \text { Prevention of Mother to Child } \\ & \text { Transmission } \\ \text { UNGASS } & \text { United Nations General Assembly } \\ & \text { Special Session } \\ \text { UNHCO } & \text { Ugandan National Health Consumers }\end{array}$




\begin{tabular}{|c|c|}
\hline UNICEF & $\begin{array}{l}\text { United Nations Children's Education } \\
\text { Fund }\end{array}$ \\
\hline VCT & Voluntary Counselling and Testing \\
\hline WHO & World Health Organization \\
\hline FHSIRB & $\begin{array}{l}\text { Faculty of Health Sciences Institutional } \\
\text { Review Board }\end{array}$ \\
\hline UNAIDS & $\begin{array}{l}\text { Joint United Nations programme on } \\
\text { HIV/AIDS }\end{array}$ \\
\hline
\end{tabular}

\section{References}

[1] Joint United Nations Program on HIV/AIDS. Report on the global AIDS epidemic [www]. Available at: http://www.unaids.org/documets/20101123-globalreport-em.pdf. [Accessed 16/06/2011]. 2010a.

[2] International HIV and AIDS charity. Prevention of mother to child transmission of HIV [www] Available at: http://www.avert.org/pmtct hiv.htm[Accessed: 10/09/2010]. 2010.

[3] Joint United Nations Program on HIV/AIDS. Unpublished estimates [www]. Available from: http://www.childinfo.org/files/opportunity_in_crisis_Report_EN052711.pdf. [Accessed 15/10/2012]. 2010b.

[4] Tsague, L. We can scale up PMTCT in low resource setting, lessons learned and challenges learned from Cameroons experience. In: the $5^{\text {th }}$ international conference on AIDS Bangkok Thailand, July 11-16. 43-60. 2004.

[5] Joanna, O., Patrice, T., Marija, M., Mukta, G., Maia, B., Fred, E., Eddy, P., Shrinivas, D., Sanjeevani, K., George, K., Eric, B., Annabel, D., Francois, D. Couple-oriented prenatal HIV counselling for HIV primary prevention. BioMed Central Public Health. 10: 197. 2010.

[6] United Nations Children's Education Fund. Cameroon PMTCT Fact Sheet. Available at: http://www.unicef.org/aids/files/cameroon-PMTCTfactsheet2010-pdf. [Accessed 15/09/2012].

[7] United Nations Children's Education Fund. Count down to zero (Eliminating new HIV infections in children by 2015 and keeping their mothers alive) Cameroon. Available at: http://www.unicef.org/aids/files/cameroon-PMTCTfactsheet2010-pdf. [Accessed 15/09/2012].

[8] Ministry of Public Health, Cameroon. Available at: http://www.cameroon-info.net/stories/0,15516,@,ministerannounces-decline-in-hiv-aids-prevalence.html [Accessed 23/08/2012]

[9] South West Regional Technical Group. Annual Report. Available at:

http://dev.cdnss.dros-minsante-cameroon.org. [Accessed 16/07/2012].

[10] Cameroon Baptist Convention. PMTCT training manual. 20-60. 2002.

[11] Academy for Educational Development and Botswana Christian AIDS Intervention Program. 2009. Male Involvement in PMTCT in Botswana. Available at: http://www.bocaip.org.bw/ [Accessed $24 / 10 / 2012]$
[12] Babirye J. Sserunga T, Rwabasonga B, M, Logose B. Male involvement in Prevention of Mother to Child Transmission of HIV. The AIDS Support Organisation (TASO) Uganda Ltd.

[13] Kayembe K, N. The role of men in the Program to prevent mother-to- child transmission of HIV in Jwaneng Botswana, University of Witwatersrand, Johannesburg. 2005.

[14] Nkuoh G. N., Meyer, D.J., Tih, P.M., Nkfusai. J. Barriers to Men's Participation in Antenatal and Prevention of Mother-to-Child HIV Transmission Care in Cameroon. African Journal of Midwifery and Women's Health. 55: 363-369. 2010.

[15] Akarro, R. R. J., Deonisia, M., Sichona, F.J. An evaluation of male involvement on the Program for PMTCT of HIV/AIDS: a case study of ilala municipality in Dar es salaam, Tanzania. Arts and Social Sciences Journal. 20-21. 2011.

[16] Stefanie, T., Paulina, M., Hebel, L., Brigitte, J., Andrea, K.G.H. Male Involvement in PMTCT Services in Mbeya Region, Tanzania. AIDS Behaviour. 13. 92-102. 2009.

[17] Barnabas, R. A., Aloysius, R., David, M., Julius, M.S., Dickson, T., Robert, T., Lillian, B. Knowledge and practices of women regarding PMTCT in Mwizi subcounty.(microresearch),Mbarara University of Science and Technology, Uganda. 23-28. 2012.

[18] United Nations General Assembly Special Session (2001). Declaration of commitment on HIV/AIDS "Global crisis Global action". Available at: http://www,un,org/ga/aids/covrage/final declarationHIVAIDS html. [Acessed 17/09/2012].

[19] Labhardt, N.D., Manga, E., Ndam, M., Balo, J. R., Bischoff, A., Stoll, B. Early assessment of the implementation of a national Program for the prevention of mother-to-child transmission of HIV in Cameroon and the effects of staff training: a survey in 70 rural health care facilities. Tropical Medicine \& International Health; 14: 288-293. 2009.

[20] Eli, F. F., Keren, M. M., Thorkild, T., Marina, M., Sia E, M., Ingunn, M. S. E. "It is her responsibility": partner involvement in prevention of mother to child transmission of HIV program, northern Tanzania. Journal of International AIDS Society; 14: 21. 2011.

[21] Lyatuu, M.B., Msamanga, G., Kalinga, A.K. Client's satisfaction with services for prevention of mother-to-child transmission of HIV in Dodoma rural district. East African Journal of Public Health. 5:174-179. 2008.

[22] Robert, B., James, K. T., Nulu, S., Thorkild, T. Determinants of male involvement in the prevention of mother-to-child transmission of HIV program in Eastern Uganda: a cross-sectional survey. Reproductive Health. 7:12. 2010.

[23] Elizabeth Glazier Paediatric AIDS Foundation. Improving the continuum of care by promoting male involvement in PMTCT in Nzega District, Tanzania. In: Nineteenth International AIDS Conference, Washington DC. 25-30. 2012.

[24] Ugba, E.A. Increasing PMTCT uptake in a rural hospital using community-based volunteers and male involvement campaigns: experience from northern Nigeria. In: Nineteenth International AIDS Conference, Washington DC. 60-87. 2012.

[25] Kikumbi, N. Will your partner be attending? Involving men in the prevention of mother-to-child transmission of HIV in antenatal care clinics in Iringa, Tanzania. In: Nineteenth International AIDS Conference, Washington DC. 60-85. 2012. 